\title{
TU/e emonownen

\section{Solvent clathrate driven dynamic stereomutation of a supramolecular polymer with molecular pockets}

\section{Citation for published version (APA):}

Kulkarni, C., Korevaar, P. A., Bejagam, K. K., Palmans, A. R. A., Meijer, E. W., \& George, S. J. (2017). Solvent clathrate driven dynamic stereomutation of a supramolecular polymer with molecular pockets. Journal of the American Chemical Society, 139(39), 13867-13875. https://doi.org/10.1021/jacs.7b07639

DOI:

10.1021/jacs.7b07639

Document status and date:

Published: 04/10/2017

\section{Document Version:}

Accepted manuscript including changes made at the peer-review stage

\section{Please check the document version of this publication:}

- A submitted manuscript is the version of the article upon submission and before peer-review. There can be important differences between the submitted version and the official published version of record. People interested in the research are advised to contact the author for the final version of the publication, or visit the $\mathrm{DOI}$ to the publisher's website.

- The final author version and the galley proof are versions of the publication after peer review.

- The final published version features the final layout of the paper including the volume, issue and page numbers.

Link to publication

\section{General rights}

Copyright and moral rights for the publications made accessible in the public portal are retained by the authors and/or other copyright owners and it is a condition of accessing publications that users recognise and abide by the legal requirements associated with these rights.

- Users may download and print one copy of any publication from the public portal for the purpose of private study or research.

- You may not further distribute the material or use it for any profit-making activity or commercial gain

- You may freely distribute the URL identifying the publication in the public portal.

If the publication is distributed under the terms of Article 25fa of the Dutch Copyright Act, indicated by the "Taverne" license above, please follow below link for the End User Agreement:

www.tue.nl/taverne

Take down policy

If you believe that this document breaches copyright please contact us at:

openaccess@tue.nl

providing details and we will investigate your claim. 


\title{
Solvent Clathrate Driven Dynamic Stereomutation of a Supramolecular Polymer with Molecular Pockets
}

\author{
Chidambar Kulkarni, ${ }^{\text {a,c }}$ Peter A. Korevaar, ${ }^{a}$ Karteek K. Bejagam, ${ }^{b}$ Anja R. A. Palmans, ${ }^{a}$ \\ E. W. Meijer, ${ }^{*, a}$ and Subi J. George*,c
}

a. Laboratory of Macromolecular and Organic Chemistry and Institute for Complex Molecular Systems (ICMS), Eindhoven University of Technology, PO Box 513, 560o MB, Eindhoven, The Netherlands

b. Chemistry and Physics of Materials Unit, Jawaharlal Nehru Center for Advanced Scientific Research (JNCASR), Jakkur, Bangaluru-560064, India

c. Supramolecular Chemistry Laboratory, New Chemistry Unit, JNCASR, Jakkur, Bangaluru-560o64, India

\begin{abstract}
Control over the helical organization of synthetic supramolecular systems is intensively pursued to manifest chirality in a wide range of applications ranging from electron spin filters to artificial enzymes. Typically, switching the helicity of supramolecular assemblies involves external stimuli or kinetic traps. However, efforts to achieve helix reversal under thermodynamic control and understanding the phenomena at a molecular level are scarce. Here we present a unique example of helix reversal (stereomutation) under thermodynamic control in the self-assembly of coronene bisimide (CBI-35CH) which has a 3,5-dialkoxy substitution on imide phenyl groups leading to "molecular pockets" in the assembly. The stereomutation was observed only if the CBI monomer possesses molecular pockets. Detailed chiroptical studies performed in alkane solvents with different molecular structure reveal that solvent molecules intercalate or form clathrates within the molecular pockets of $\mathbf{C B I}-35 \mathbf{C H}$ at low temperature $(263 \mathrm{~K})$, thereby triggering the stereomutation. The interplay between helical assembly, molecular pockets and solvent molecules is further unraveled by explicit solvent molecular dynamics simulations. Our results demonstrate how the molecular design of self-assembly building blocks can orchestrate the organization of surrounding solvent molecules, which in turn dictates the helical organization of the resulting supramolecular assembly.
\end{abstract}

\section{Introduction:}

Helical assemblies are ubiquitously found in nature and have been a source of inspiration for chemists to emulate elegant optically active architectures. ${ }^{1-3}$ The molecular recognition and catalytic activity of bio-macromolecules rely heavily on their three-dimensional helical structure.4,5 Synthetic helical structures can act as mimics to biological counterpart aiding to elucidate the role of chiral organization in biological functions. In addition, the chirality of a system is pivotal in realizing new applications such as molecular motors ${ }^{6}$ and spin-filters ${ }^{7,8}$. Thus control over the helicity of macromolecules has been a topic of intense study. Synthetic helical structures are typically obtained through three approaches; i) conformationally restricted macromolecules, ${ }^{9-11}$ ii) self-assembly of chiral monomers/polymers ${ }^{12}$ and iii) induction of chirality to assembled structure through chiral solvents, ${ }^{13,14}$ circularly polarized light, ${ }^{15}$ and chiral auxillary ${ }^{16}$.

Stereomutation or dynamic switching of helicity is an important tool to control the helicity of an assembly. Covalent polymers such as regioregular poly(thiophene)s, ${ }^{17}$ poly( $\beta$-phenylpropyl L-aspartate), ${ }^{18}$ poly(silane) $\mathbf{s}^{19-22}$ and poly(quinoxaline-2,3-diyl) $\mathrm{s}^{23-26}$ with pendant chiral side chains and low helix reversal barrier exhibit switchable helical behaviour. Supramolecular polymers are inherently more dynamic than covalent counterparts due to the weak non-covalent interaction between the monomeric units $^{27}$ and are thus more suited for harnessing the dynamic helicity. Stereomutation has been observed in a variety of supramolecular systems and it can be broadly divided into two categories; i) due to stimuli such as $\mathrm{pH}^{28}$ light, ${ }^{15}$ guests, ${ }^{29-31}$ solvents, ${ }^{32,33}$ and coassembly ${ }^{34}$ and ii) due to kinetic traps or pathway complexity. The investigation into the latter category of systems has steeply increased in the last few years. The process of self-assembly of a monomer into more than one kind of aggregates with at least one of them being a kinetic state has been termed as "pathway complexity" 35 and it has been observed in self-assembled systems such as oligo( $p$ phenylenevinylene), ${ }^{36}$ merocyanines, 37 bipyridine substituted benzene-1,3,5-tricarboxamides (BTA), ${ }^{38}$ perylene bisimides, ${ }^{39}$ triphenylamines, ${ }^{40}$ porphyrins, ${ }^{41}$ oligo( $p$ phenylene $)^{42}$ and $\mathrm{N}$-heterotriangulenes ${ }^{43}$ among others. Kinetic control by mastering pathway complexity can lead to living-supramolecular polymerization as demonstrated by Takeuchi, Sugiyasu et al.44,45 Recently, transient helici- 
ty or fuel-driven stereomutation has also been observed for out-of-equilibrium self-assembly. ${ }^{46}$

The thermodynamic and/or kinetic stability of a system depends on experimental conditions of self-assembly such as (co)-solvent and temperature. Solvent molecules have been shown to play a major role in the assembly process. ${ }^{47-49}$ In addition, the observation of chiral solvents inducing helicity into achiral assemblies ${ }^{14,50,51}$ further confirms the active role of solvents in the self-assembly process. Moreover, there have been studies in which opposite helical bias is observed under thermodynamic control by the participation of apolar solvents (linear vs branched) $)^{33,52}$ or mixture of two polar solvents ${ }^{32,53,54}$. However, systems where stereomutation under thermodynamic control is directed by the molecular design of the building blocks that governs the organization of solvent molecules have not been reported.

Here we present an example of a synthetic helical assembly in which solvent molecule incorporation into a molecular pocket leads to dynamic stereomutation at low temperature, analogous to binding of guest molecules to enzymes leading to significant conformational change, thus modulating their activity. During the course of our investigation on the self-assembly of coronene bisimides (CBIs), 55 we serendipitously observed the helix inversion for CBI derivative (CBI-35CH) possessing a bis $\left((S)-3,7^{-}\right.$ dimethyloctyloxy)phenyl substituent on the imide position. Due to the 3,5-position of the alkoxy chains on the phenyl, the molecule possesses a cavity or pocket accessible to solvents. We have investigated this dynamic stereomutation process in detail by electronic circular dichroism studies by varying the molecular structure of monomer and solvent used for self-assembly to understand the origin of helix inversion. Remarkably, the stereomutation is completely under thermodynamic control and reversible. Based on explicit solvent molecular dynamics (MD) simulations and experimental studies, we show that the solvent-accessible pocket in $\mathbf{C B I}-\mathbf{3 5} \mathbf{C H}$ assembly is responsible for the helix inversion. Thus the present work exemplifies the role of monomer structure and solvents in dictating the handedness of a supramolecular assembly.

\section{Results:}

The molecules under study consist of a coronene bisimide core with phenoxy substituents on imide positions (Figure 1a). The phenoxy moiety with 3,5-dialkoxy substitution (both chiral (CBI-35CH) and achiral (CBI-35ACH)) and 3,4,5-trialkoxy substitution (gallic moiety, both chiral (CBI-GCH) and achiral (CBI-GACH)) have been investigated. The 3,5-disubstitution creates a molecular pocket in the resulting assemblies for the incorporation of guest or solvent molecules (Figure $\mathbf{1 b}$ ). $\mathbf{C B I}-35 \mathbf{C H}$ and $\mathbf{C B I}-$ $35 \mathrm{ACH}$ were synthesized by the imidation of coronene dianhydride ${ }^{5}$ with the corresponding phenyl amine in freshly distilled quinoline and both the molecules were thoroughly characterized using ${ }^{1} \mathrm{H}$ - and ${ }^{13} \mathrm{C}-\mathrm{NMR}$ spectroscopy and MALDI-TOF mass spectrometry (see SI ex

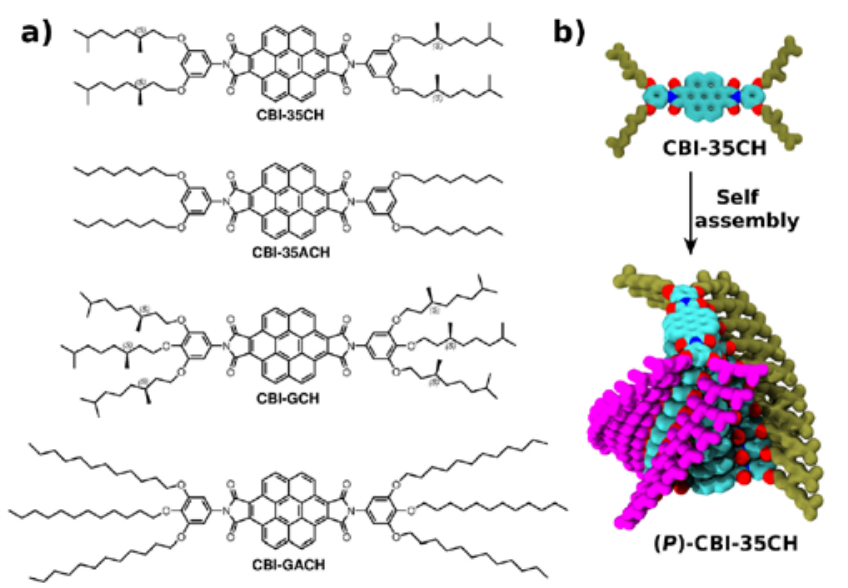

Figure 1: a) Molecular structure of the coronene bisimides (CBIs) involved in this study. b) Schematic representation of the self-assembly of $\mathbf{C B I}-35 \mathbf{C H}$. The phenoxy group on one of the imides is colored magenta, highlighting the molecular pocket that is formed in the periphery of the assembly. Only one possible helicity is shown.

perimental section for details). The synthesis and characterization of CBI-GCH and CBI-GACH has been reported before. 55

\section{Self-assembly of CBI-35CH}

The self-assembly of all the coronene bisimides has been studied mainly through UV/vis absorption and electronic circular dichroism (CD) spectroscopy in apolar solvents. Both $\mathbf{C B I}-35 \mathrm{CH}$ and $\mathbf{C B I}-35 \mathrm{ACH}$ are weaklyfluorescent even in the molecularly dissolved state due to electron transfer from the phenoxy wedge to the CBI core, as observed in the case of CBI-GCH and CBI-GACH. ${ }^{55}$

$\mathrm{UV} /$ vis absorption spectrum of $\mathbf{C B I}-35 \mathbf{C H}$ in $\mathrm{MCH}(c=$ $\left.5 \times 10^{-5} \mathrm{M}\right)$ at $288 \mathrm{~K}$ shows a maximum at $325 \mathrm{~nm}$ with broad band between 450 to $550 \mathrm{~nm}$. At higher temperature, the absorption maximum red-shifts to $332 \mathrm{~nm}$ with the appearance of a shoulder and the bands at 450, 477, and $488 \mathrm{~nm}$ become sharp (Figure 2a). The hypsochromic shift in absorption maximum at low temperatures suggests the H-type aggregation of $\mathbf{C B I}-35 \mathbf{C H}$ in $\mathrm{MCH}$. The corresponding $\mathrm{CD}$ spectra at $288 \mathrm{~K}$ shows a bisignated Cotton effect with almost equal magnitude of the molar circular dichroism (with $\Delta \varepsilon$ of -14.9 and $+13.36 \mathrm{~L} \mathrm{~mol}^{-1} \mathrm{~cm}^{-}$ ${ }^{1}$ at 320 and $361 \mathrm{~nm}$, respectively, Figure 2b), indicating that the chirality of the side chains has been transferred to the supramolecular level. The zero crossing points in the CD spectrum (at $\lambda=476,463$ and $328 \mathrm{~nm}$ ) coincide with the maxima in the UV/vis absorption spectrum (at $\lambda$ $=478,468$ and $328 \mathrm{~nm}$ ), indicating that the $\mathrm{CD}$ spectrum originates from exciton coupling between the neighboring CBI molecules. Since the Cotton effect has a positive couplet at the longer wavelength (around $500 \mathrm{~nm}$ ), the assemblies have been ascribed to $(P)$-type helicity. At higher temperatures $(368 \mathrm{~K})$ the Cotton effect vanishes, due to the lack of interaction between monomers leading to a molecular dissolved state (Figure $2 \mathrm{~b}$ ). Thus, the selfassembly of 

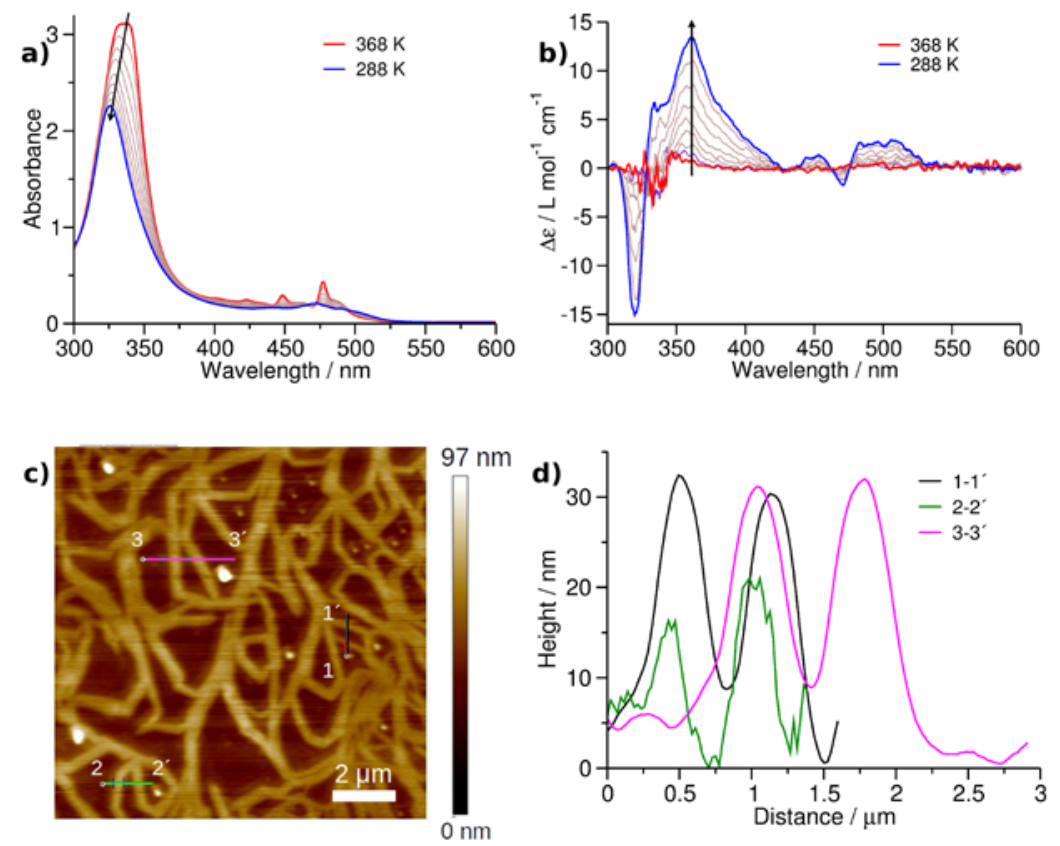

Figure 2: Self-assembly of $\mathbf{C B I - 3 5 C H . ~ a ) ~ a n d ~ b ) ~ t e m p e r a t u r e - d e p e n d e n t ~ U V / v i s ~ a n d ~ C D ~ s p e c t r a , ~ r e s p e c t i v e l y , ~ o f ~} \mathbf{C B I - 3 5} \mathbf{C H}$ in $\mathrm{MCH}\left(c=5 \times 10^{-5} \mathrm{M}\right)$. Arrows indicate spectral changes with decrease in temperature. c) Tapping mode atomic force microscopy (AFM) image of a film of $\mathbf{C B I}-35 \mathbf{C H}$ obtained by drop-casting a solution in $\mathrm{MCH}\left(c=1 \times 10^{-4} \mathrm{M}\right)$ on a clean glass substrate. d) Height profile analysis along the lines marked in c).

CBI-35CH is primarily driven by the $\pi-\pi$ stacking of the coronene bisimides and the van der Waals interactions of the peripheral phenoxy wedges.

The CBI-35CH assemblies were visualized using tapping mode atomic force microscopy (AFM) on a thin film (obtained by drop-casting a $1 \times 10^{-4} \mathrm{M}$ solution in $\mathrm{MCH}$ ) on a freshly cleaned glass substrate. The microscopy images display a network of fibrillar structures on a micrometer length scale (Figure 2c). This suggests the 1-D selfassembly of $\mathbf{C B I}-35 \mathbf{C H}$. The height profile showed dimensions in the range of $0-30 \mathrm{~nm}$ for various fibers (Figure 2d). The individual molecular dimensions are much smaller ( $0.6 \mathrm{~nm})$ than those obtained upon height analysis, suggesting that the fibers observed in AFM are rather bundles of multiple individual fibers. Also, the macromolecular helicity of the bundles was not discernible through AFM studies.

After visualizing the 1-D assembly of $\mathbf{C B I}-35 \mathbf{C H}$, we investigated the mechanism of supramolecular polymerization using temperature-dependent $C D$ studies at various concentrations. Cooling curves obtained by monitoring the Cotton effect at $320 \mathrm{~nm}$ at different cooling rates (0.5, 1 and $2 \mathrm{~K} \mathrm{~min}^{-1}$ ) were identical (Figure $\mathrm{S} 1$ ), indicating that the supramolecular polymerization occurs under thermodynamic control. The cooling curves showed a gradual transition from monomers at high temperature to selfassembled state at $283 \mathrm{~K}$. The normalized cooling curves could be well described by the isodesmic model 57 of selfassembly (Figure 3). Further, the various thermodynamic parameters governing the self-assembly have been obtained from non-linear regression analysis of cooling curves and Van't Hoff plots at various concentrations (Figure S2) and are detailed in Supporting Information Table $\mathrm{S}$. The melting temperature $\left(T_{\mathrm{m}}\right)$ of the assembly changes by $10 \mathrm{~K}$ over an order of magnitude change in concentration.

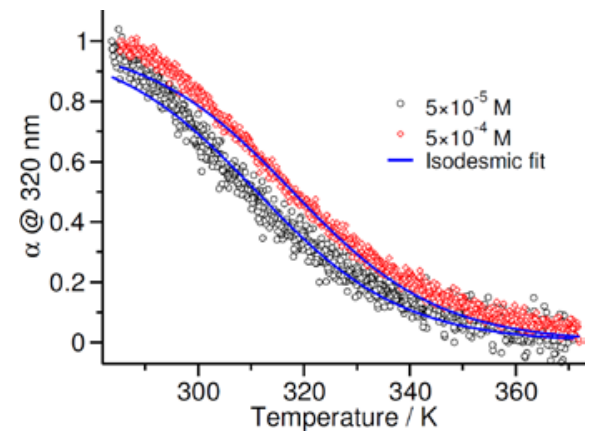

Figure 3: Mechanism of self-assembly of $\mathbf{C B I}-35 \mathrm{CH}$ in $\mathrm{MCH}$. The normalized fraction of aggregates $(\alpha)$ as a function of temperature, was obtained from temperature-dependent CD cooling studies (cooling rate $2 \mathrm{~K} \mathrm{~min}^{-1}$ ).

\section{Dynamic reversal of supramolecular chirality in MCH}

When the solution of $\mathbf{C B I}-\mathbf{3 5} \mathbf{C H}$ in $\mathrm{MCH}$ was cooled below $283 \mathrm{~K}$, we observed that the sign of the Cotton effect reversed (Figure 4a). Intrigued by this reversal of the sign, the CD cooling curves were recorded till $263 \mathrm{~K}$ at various concentrations. The reversal of supramolecular 

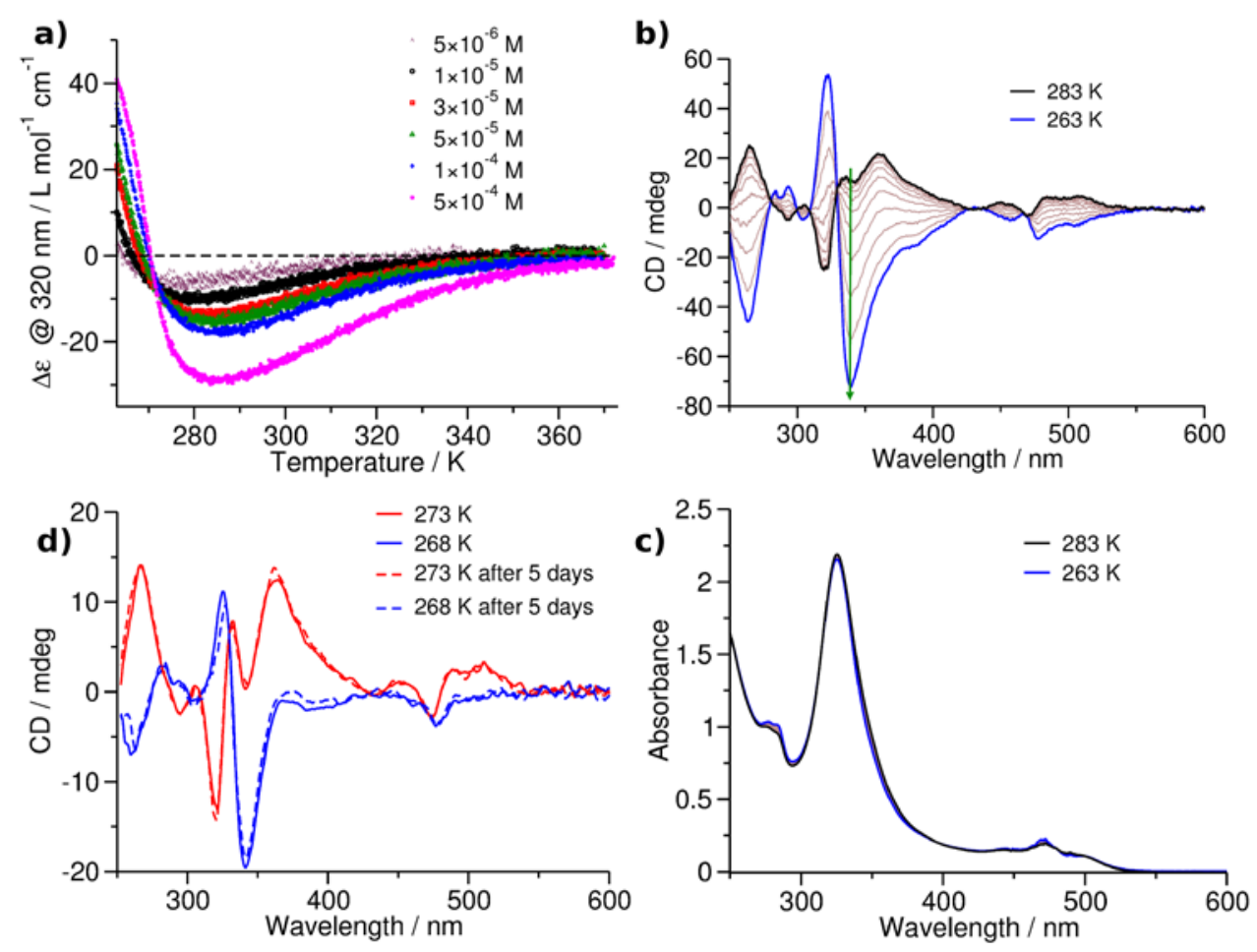

Figure 4: Stereomutation of $\mathbf{C B I}-\mathbf{3 5} \mathbf{C H}$ assemblies in $\mathrm{MCH}$ at lower temperatures. a) Cooling curves at different concentrations obtained from CD studies (cooling rate $=2 \mathrm{~K} \mathrm{~min}^{-1}$ ). b) and c) Variable-temperature CD and UV/vis spectra respectively $\left(c=5 \times 10^{-5} \mathrm{M}\right)$ from $283 \mathrm{~K}$ to $263 \mathrm{~K}$ (spectra are shown every $2 \mathrm{~K}$ ). Arrow indicates spectral changes with decrease in temperature. d) Time-dependent $\mathrm{CD}$ spectra $\left(\mathrm{c}=5 \times 10^{-5} \mathrm{M}\right)$ at $273 \mathrm{~K}$ and $268 \mathrm{~K}$ immediately after solution preparation and after 5 days, indicating that both the states are under thermodynamic control. All studies were performed in a $10 \mathrm{~mm}$ path length cuvette.

helicity (or sign of Cotton effect) was observed at all concentrations (Figure 4a and Figure $\mathrm{S}_{3}$ ), albeit that the temperature at which the CD signal crosses zero (termed as transition temperature, $T_{\mathrm{o}}$ ) increased with increase in concentration (Figure $\mathrm{S}_{4}$ ). A temperature versus concentration pseudo-phase diagram was constructed to examine the concentration dependence of both self-assembly and stereomutation process, as has been previously reported for (D)-BTA.33 The $T_{\mathrm{o}}$-line shows a much weaker dependence on concentration compared to the $T_{\mathrm{m}}$-line (Figure $\mathrm{S}_{5}$ ). The weak but finite concentrationdependence of the stereomutation process suggests that the degree of polymerization or stack length affects the stereomutation process.

$\mathrm{CD}$ and UV/vis spectra were recorded every $2 \mathrm{~K}$ to observe the spectral changes as a function of temperature. The stereomutation process is evident from the CD spectra which show isodichroic points at $\lambda=469,432,329$, and $309 \mathrm{~nm}$ (Figure 4b). The CD spectra at $283 \mathrm{~K}$ and 263 $\mathrm{K}$ are not exact mirror images of each other, indicating that the $(M)$-supramolecular helicity at $263 \mathrm{~K}$ is diastereomerically related to the $(P)$-helicity observed at higher temperatures. On further decreasing the temperature to $218 \mathrm{~K}$, the sign of the Cotton effect was retained and only the magnitude increased (Figure S6). Remarkably, the UV/vis absorption spectra do not show any change be- tween 283 and $263 \mathrm{~K}$ (Figure 4c). This clearly indicates that inversion in supramolecular helicity is not due to further self-assembly of $\mathbf{C B I}-\mathbf{3 5} \mathbf{C H} . .^{8}$ Often, such reversal of helicity in supramolecular systems have been attributed to kinetic processes. ${ }^{36}$ To examine that, we have recorded full cooling and heating curves at three different rates (i.e. $0.5,1$ and $2 \mathrm{~K} \mathrm{~min}^{-1}$ ). All the cooling and heating curves coincide over the entire spectral range (Figure $S_{7}$ ). $\mathrm{CD}$ spectra in $\mathrm{MCH}\left(c=5 \times 10^{-5} \mathrm{M}\right)$ corresponding to the $(P)-($ at $273 \mathrm{~K})$ and $(M)$-helicity (at $268 \mathrm{~K})$ were identical even after keeping solution at room temperature for 5 days (Figure $4 \mathrm{~d}$ ). This suggests that the $(M)$-helicity observed at low temperature does not depend on the path taken to reach it, but corresponds to another thermodynamic state determined solely by temperature.

Table 1: Thermodynamic parameters for the selfassembly of $\mathrm{CBI}-35 \mathrm{CH}$ in $\mathrm{MCH}$.

\begin{tabular}{ccc}
\hline $\begin{array}{c}\text { Enthalpy, } \\
\Delta H\end{array}$ & Entropy, & Free energy, \\
$\left.(\mathrm{kJ} \mathrm{mol})^{-1}\right)$ & $\Delta S$ & $\Delta G$ \\
$\left(\mathrm{~kJ} \mathrm{~mol}^{-1} \mathrm{~K}^{-1}\right)$ & $\left(\mathrm{kJ} \mathrm{mol}^{-1}\right)^{[\mathrm{b}]}$ \\
\hline$-67.77^{[\mathrm{a}]}$ & $-0.146^{[\mathrm{a}]}$ & -26.45 \\
\hline
\end{tabular}

[a] These are average values taken from Table $\mathrm{S}_{1}$ and [b] Calculated at $283 \mathrm{~K}$. 

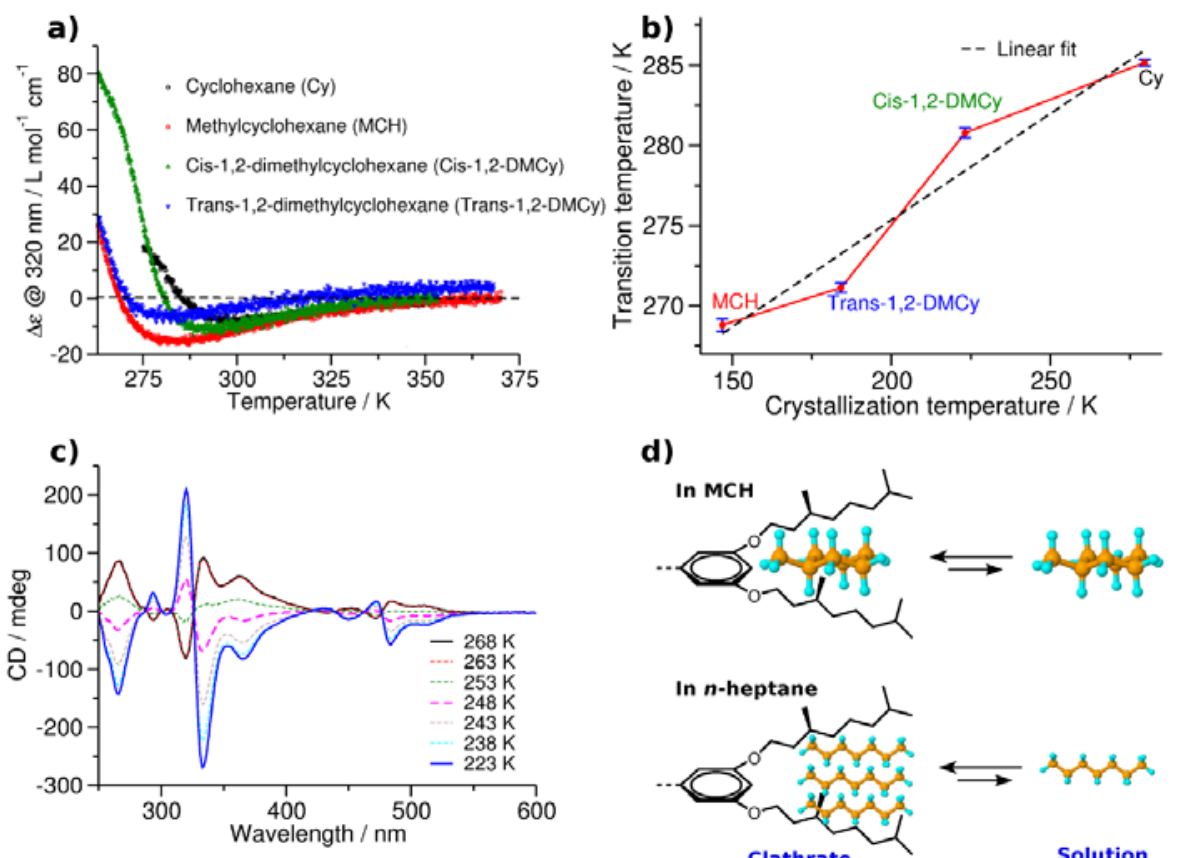

d)
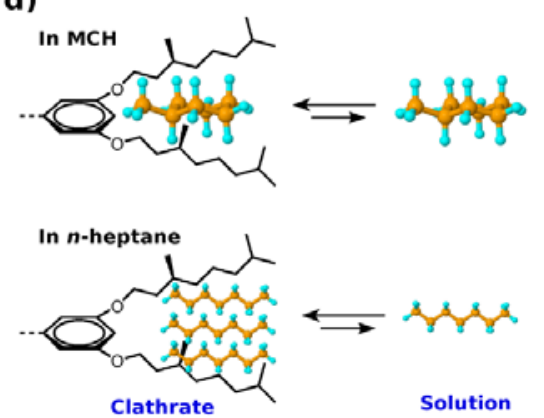

Figure 5: $\mathrm{CD}$ studies on the stereomutation of $\mathbf{C B I}-\mathbf{3 5} \mathbf{C H}$ assemblies in cyclic and linear solvents. a) Cooling curves obtained from CD studies of $\mathbf{C B I}-35 \mathrm{CH}$ in various cyclic solvents $\left(c=5 \times 10^{-5} \mathrm{M}, 2 \mathrm{~K} \mathrm{~min}^{-1}\right)$. b) Plot of transition temperature (the temperature at which the $C D$ effect is zero while cooling from high to low temperature, obtained from Figure $5 \mathrm{a}$ ) versus the crystallization temperature of respective solvent (melting point). c) CD spectra of $\mathbf{C B I}-35 \mathbf{C H}$ in $n$-heptane $\left(c=6.5 \times 10^{-5} \mathrm{M}\right)$ at low-temperatures. d) A schematic representation of the solvent intercalation into the molecular pocket at low temperature leading to helicity reversal. $\mathrm{MCH}$, being a cyclic solvent, fits into the pocket better compared to $n$-heptane for which a small cluster of molecules is needed to completely occupy the molecular pocket.

\section{Solvent effect in reversal of helicity}

After confirming that the inversion in helicity does not correspond to kinetically trapped or metastable states, we have further studied the role of solvent to get better insight into the helix inversion. CD cooling curves were recorded in a range of cyclic solvents such as cyclohexane (Figure S8), cis- and cis/trans-1,2-dimethylcyclohexane mixture (Figure S9 \& 10) and cis/trans-decalin mixture (Figure S11). The inversion in helicity was observed in all the solvents but the transition temperature is different for each of the solvents. Surprisingly, a plot of transition temperature versus the crystallization temperature of the cyclic solvents ${ }^{59}$ shows a linear trend (Figure $5 \mathrm{~b}, \mathrm{R}^{2}=$ o.96). One plausible explanation of the linear trend would be the following; intercalation of solvent molecules into the molecular pockets available in the phenoxy part of CBI-35CH assembly, leading to its rigidification at low temperatures, is a process analogous to crystallization. The inversion of chirality was also observed in branched solvents such as iso-octane (Figure S12). In all the cases, no change in UV/vis absorption spectra was observed going from $(P)$ - to $(M)$-helicity.

In addition to cyclic and branched solvents, selfassembly of $\mathbf{C B I}-35 \mathrm{CH}$ was also studied in a linear chain alkane such as $n$-heptane. Unlike the cyclic solvents, no inversion in handedness was observed for $\mathbf{C B I}-35 \mathrm{CH}$ in $n$ heptane $\left(c=6.5 \times 10^{-5} \mathrm{M}\right)$ until $263 \mathrm{~K}$. On decreasing the temperature to $253 \mathrm{~K}$, the Cotton effect decreased in magnitude. Further decrease in temperature resulted in the complete inversion of supramolecular helicity with several isodichroic points (Figure 5c), indicating the existence of only two kinds of chiral assemblies. Again minimal changes were observed in the UV/vis absorption spectra at low temperatures (Figure $\mathrm{S}_{13}$ ). We envisage that, due to the linear structure of $n$-heptane, a finite number of solvent molecules or a small molecular cluster of $n$-heptane would be required to completely satisfy the molecular pocket of $\mathbf{C B I}-35 \mathbf{C H}$ through intercalation (Figure $5 \mathrm{~d}$ ). The process of forming a cluster of $n$-heptane within the pocket of $\mathbf{C B I}-35 \mathbf{C H}$ requires lower temperature, also resulting in a significantly lower transition temperature $(\sim 253 \mathrm{~K})$ with $n$-heptane as the solvent. ${ }^{60}$

\section{Role of molecular structure}

The conjecture that the molecular pockets in $\mathbf{C B I}-35 \mathbf{C H}$ self-assembly play a dominant role in controlling the helix reversal was examined by $\mathrm{CD}$ studies of similar CBI derivatives with structural mutations in the gallic moiety. First the 3,4,5-tris((S)-3,7-dimethyloctyoxy)phenyl substituted CBI (CBI-GCH) which does not possess a molecular pocket was studied by $\mathrm{CD}$ spectroscopy at low temperatures. CBI-GCH was earlier observed to form $(P)$-type helix in $\mathrm{MCH}$ in the assembled state, 55 analogues to the chiroptical behavior of CBI-35 CH assembly. 

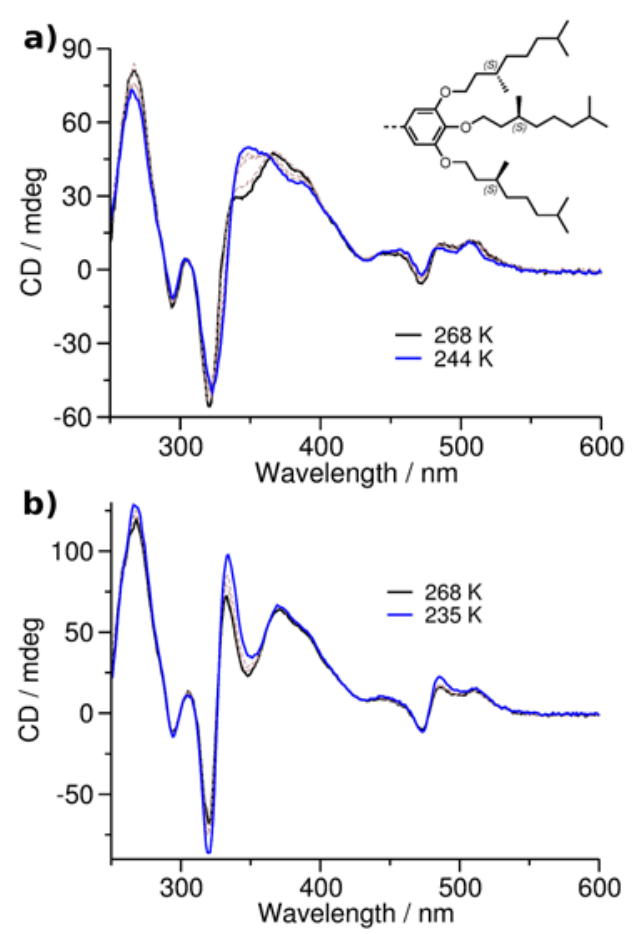

Figure 6: Helical assembly of CBI derivative with no molecular pocket. Variable-temperature CD spectra of CBI-GCH in $\mathrm{MCH}$ (a) and $n$-heptane (b) do not show stereomutation at low temperatures $\left(c=5 \times 10^{-5} \mathrm{M}\right)$. Inset of a) shows the structure of gallic substitution pattern.

CD spectra of CBI-GCH in both cyclic (MCH) and linear (n-heptane) solvents retained the $(P)$-helicity until $235 \mathrm{~K}$ (Figure 6a and $\mathrm{b}$ ), in contrast to the reversal observed for CBI-35CH at such low temperatures. We envisage that, due to the closely substituted alkyl chains in the gallic wedge, CBI-GCH lacks a molecular pocket and thus the approach of solvent molecules into CBI-GCH assembly will be hindered. This further shows the important role of the molecular pocket in dictating the reversal.

Furthermore, the role of molecular pocket was investigated by CD studies of achiral CBIs with both 3,5- and 3,4,5alkoxyphenyl substituents on the imide region in chiral solvents to investigate the efficiency of chiral induction based on molecular structures. Previously, it has been shown that preferential solvation of a supramolecular assembly by chiral solvents leads to chiral induction, ${ }^{14,50,51}$ thus showing that proximity of chiral solvent is important to achieve induction of chirality. CBI-35ACH forms $\mathrm{H}$ type aggregates in $\mathrm{MCH}$, similar to that observed for the CBI-35CH (Figure S14). On cooling a solution of CBI$35 \mathrm{ACH}$ in $(S)$-limonene from molecularly dissolved state $(\sim 368 \mathrm{~K})$ to $293 \mathrm{~K}$, the UV/vis spectra show characteristics of self-assembly. The normalized fraction of aggregates $(\alpha)$ at $293 \mathrm{~K}$ obtained from CD and UV/vis cooling curve are 0.04 and 0.78 , respectively (Figure $\mathrm{S}_{15} \mathrm{~b}$ ). This indicates that chiral induction does not take place

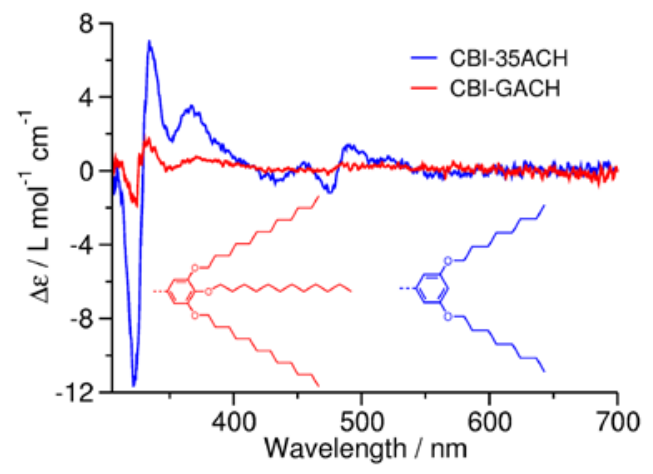

Figure 7: Assembly of achiral CBI derivatives with chiral solvent. CD spectra of CBI-35ACH and CBI-GACH in $(S)$ limonene at $263 \mathrm{~K}\left(c=5 \times 10^{-5} \mathrm{M}\right)$. The molecular structure of the substitution pattern on gallic moiety are shown in the inset of $b$ ).

till $293 \mathrm{~K}$ although aggregation sets in earlier (Figure $\mathrm{S}_{15}$ ). On further cooling from $293 \mathrm{~K}$ to $263 \mathrm{~K}$ the induced Cotton effect is observed without significant changes in the absorption spectra (Figure S16). This clearly suggests that once the $\mathbf{C B I}-35 \mathbf{A C H}$ reaches a certain extent of aggregation then the chiral solvent molecules intercalates into the pocket of the assembly leading to induced bisignate Cotton effect (Figure 7). Induced CD spectrum for CBI$35 \mathrm{ACH}$ observed in $(R)$-limonene was exactly the mirror image of that recorded in (S)-limonene (Figure $\mathrm{S}_{17}$ ), thus reaffirming that the $\mathrm{CD}$ spectra are due to the chirality transfer from solvent to the chromophore (CBI). On the other hand, similar studies on CBI-GACH (with 3,4,5trialkoxy phenyl) showed only a very weak induced Cotton effect between 305-350 nm (Figure 7). The molar ellipticity $(\Delta \varepsilon)$ at $322 \mathrm{~nm}$ for CBI-35ACH and CBI-GACH in (S)-limonene are -11.68 and $-1.6 \mathrm{~L} \mathrm{~mol}^{-1} \mathrm{~cm}^{-1}$, respectively (Figure 7). The difference in the extent of chiral induction $(\Delta \varepsilon)$ between the CBI-35ACH and CBI-GACH clearly indicates the increased proximity of solvents with the $\mathrm{CBI}$ core through the molecular pocket for the former. Thus, the influence of molecular pocket is also reflected in the extent of chiral induction by $(S)$-limonene.

\section{Molecular dynamics (MD) simulations}

In order to gain a molecular level understanding of the interplay between CBI assemblies and solvent molecules, molecular dynamics simulations were carried out. Preformed $(M)$ - and $(P)$-stacks of size 15 were soaked in wellequilibrated cyclohexane solvent for $5 \mathrm{~ns}$. Given the small system size and high concentration, it is difficult to observe the reversal of handedness in the MD simulation at temperatures used in the experiments. Thus, two extreme temperatures ( $250 \mathrm{~K}$ and $350 \mathrm{~K}$ ) have been chosen to understand the stereomutation process. Simulations were performed in isothermal-isobaric ensemble (NPT) for 20 ns and the last 12 ns were used for all the analysis. Additional simulation details are given in Supporting Information. 

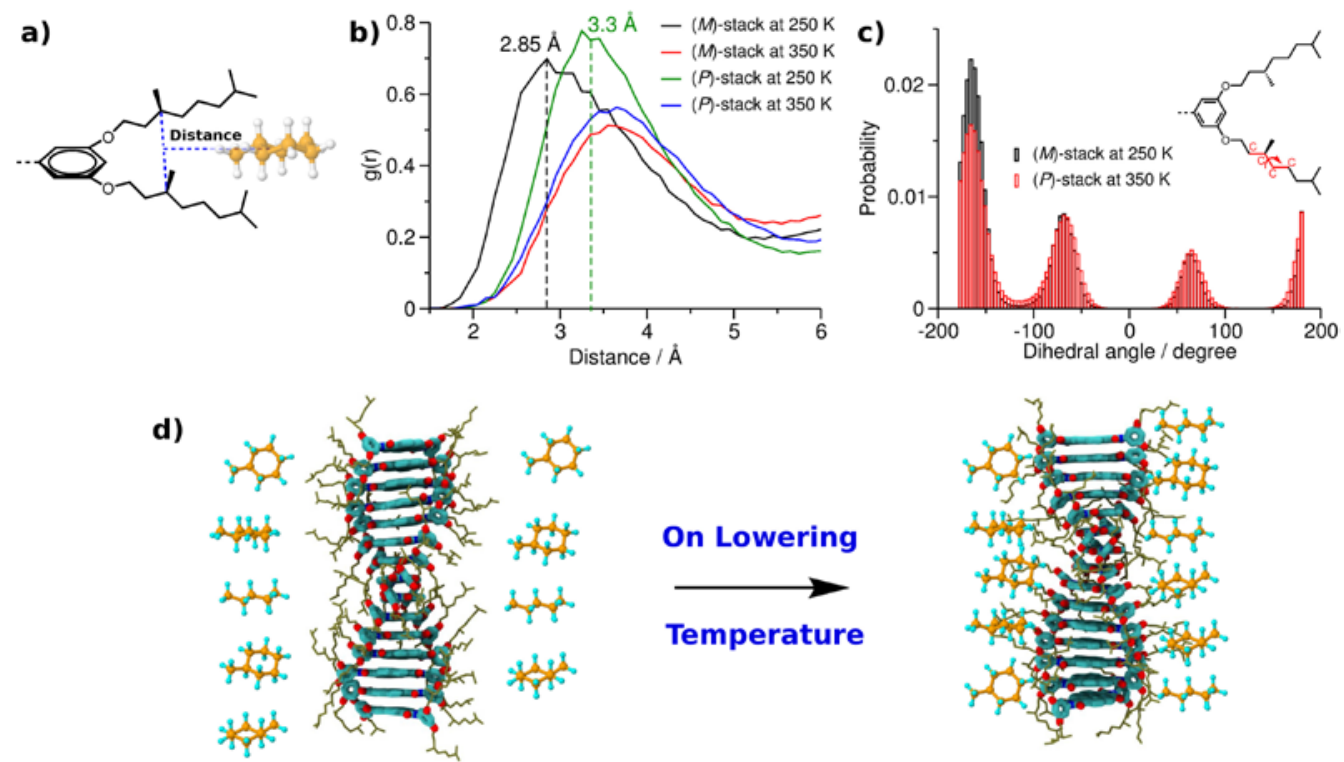

At $283 \mathrm{~K},(P)$-Helicity

\section{At $263 \mathrm{~K},(M)$-Helicity}

Figure 8: Molecular dynamics (MD) simulations on intercalation of MCH solvent molecules within molecular pocket of CBI-35CH assemblies: a) Pictorial representation of the distance between the center of mass of chiral carbon atom on the phenoxy wedge to the center of mass of the solvent molecule (MCH). b) The distance defined in a) was used to obtain the pair correlation $(\mathrm{g}(\mathrm{r}))$ plotted at different temperatures. See supporting information Figure S18 for the full g(r) graph. c) Probability distribution of $\mathbf{C B I}-\mathbf{3 5} \mathbf{C H}$ as a function of dihedral angle. The Scanned dihedral angle is shown in the inset. d) A pictorial representation of the stereomutation process. At $283 \mathrm{~K}$, the solvent molecules form a sheet around an assembly, whereas at $263 \mathrm{~K}$ the solvents intercalate or form clathrates with assembly leading to inversion of helicity.

To quantify the occupation of solvent molecules in the pocket of $\mathbf{C B I}-35 \mathbf{C H}$, the pair correlation function $(g(\mathrm{r}))$ between the center of mass of solvent molecules and the center of mass of stereocenters on one of the arms of CBI${ }_{35} \mathrm{CH}$ molecules (Figure $8 \mathrm{a}$ ) at $250 \mathrm{~K}$ was compared to 350 $\mathrm{K}$. At $250 \mathrm{~K}$, solvent molecules can intrude deeper into the pocket of a $(M)$-stack $(2.85 \AA)$ than a $(P)$-stack $(3.3 \AA)$, favoring $(M)$-type helicity (Figure $8 \mathrm{~b}$ and Figure $\mathrm{S} 18$ ). However, at $350 \mathrm{~K}$, the $g(\mathrm{r})$ peaks at exactly the same distance for both $(P)$ - and $(M)$ - stacks (Figure $8 \mathrm{~b}$ ). As a result, at elevated temperatures the solvent interaction with CBI-35CH molecules is similar for $(M)$ - and $(P)$-stacks, and the chirality present in the side chains determines the handedness of the oligomer, favoring $(P)$-type helicity.

Distance distributions between the chiral centers of adjacent molecules within the same helix were determined (Figure S19). At lower temperatures, these distributions are narrow and short, indicative of chiral centers that strongly interact while at the same time leaving the molecular pocket wider. At high temperatures, interaction between the chiral centers is weak and thus, the tails are disordered resulting in decreased pocket accessibility. Furthermore, using the dihedral angle as depicted in inset of Figure 8c, we have quantified the dihedral angles of four arms for $(M)$-stack at $250 \mathrm{~K}$ and $(P)$-stack at $350 \mathrm{~K}$. Trans-conformation of the dihedral angle (around $\pm 180^{\circ}$ ) refers to a wider pocket while gauche-conformation (around $\pm 80^{\circ}$ ) hints towards a decreased accessibility of the pocket. It is evident that the trans-conformations in- crease with decreasing temperature (Figure 8c), thus widening the pocket for approach of solvent molecules. This again points to the increased probability of accommodating the solvent molecules at low temperature. Further, semi-empirical (ZINDO) based computation on $(P)$ - and $(M)$-dimer obtained from MD-simulation exhibit opposite helicity (Figure S2O), which is in accordance with reversal of supramolecular chirality observed for CBI-35CH (Figure 4 b).

To corroborate the effect of solvent intercalation on the helicity at low temperature, simulations were performed for CBI-GCH, which lacks a molecular pocket. Pair correlation function $(g(r))$ between the center of mass of solvent molecules and center of mass of stereocenters on one of its arm show negligible difference at two temperatures (see Figure S21). This clearly indicates that even at low temperatures the solvent molecules do not intercalate into the assembly of CBI-GCH. The $g(\mathrm{r})$ peaks at $\sim 3 \AA$ and $9 \AA$ for $\mathbf{C B I}-35 \mathbf{C H}$ and $\mathbf{C B I}-\mathbf{G C H}$, respectively, further reaffirming the proximal distance of solvents molecules to assembly of $\mathbf{C B I}-35 \mathbf{C H}$.

\section{Discussion:}

The stereomutation observed for $\mathbf{C B I}-\mathbf{3 5} \mathbf{C H}$ assembly at low temperature can be attributed to the molecular pocket of $\mathbf{C B I}-35 \mathrm{CH}$ due to the following reasons; i) The stereomutation is observed in various cyclic alkane solvents and the transition temperature $\left(T_{\mathrm{o}}\right)$ correlates directly to the crystallization temperature of the solvents, indicating 
that a process similar to crystallization of solvents is occurring. ii) CBI-GCH, which lacks a molecular pocket, does not show stereomutation until $235 \mathrm{~K}$ in both linear and cyclic alkane solvents. iii) The induction of chirality to an assembly of achiral CBI-35ACH from solvents such as $(S)$-limonene occurs only at low-temperature $(<293 \mathrm{~K})$. This suggests that - similar to cyclic alkanes, (S)limonene molecules enter the molecular pocket at lower temperatures, and induce chirality to the system. This is further strengthened by the fact that for achiral CBIGACH, which lacks a molecular pocket, the extent of chiral induction is 10 times lower compared to $\mathbf{C B I}-35 \mathbf{A C H}$. iv) Finally, explicit solvent MD simulations show that for CBI-35CH the solvent molecules approach the pocket much closer at low temperature. For CBI-GCH however, MD simulations show a solvent approach as well as handedness of the assembly that is invariant of the temperature. Thus, based on these results we envisage that CBI${ }_{35} \mathrm{CH}$ assemblies and solvent molecules form clathrates or inclusion complexes at low-temperature $(<283 \mathrm{~K})$ leading to inversion in handedness of the assembly (Figure 8d).

\section{Conclusions:}

We have investigated the self-assembly of $\mathbf{C B I}-35 \mathbf{C H}$ in detail with chiroptical spectroscopy. CBI-35CH selfassembles into 1-D structures through an isodesmic mechanism of self-assembly. Furthermore, CBI-35CH showed dynamic reversal of supramolecular helicity at low temperatures $(<283 \mathrm{~K})$. The reversal was observed in a range of cyclic, linear and branched solvents. The inversion is completely under thermodynamic control and the sign and magnitude of the Cotton effect depends only on the temperature. The role of molecular building blocks in governing the stereomutation has been investigated in detail by varying the substitution pattern of alkoxy chains of gallic moiety (3,4,5-trialkoxy phenyl). Although the gallic moiety is commonly used for providing solubility to self-assembling molecular building blocks, the disposition of the alkoxy groups needs careful attention as it can lead to stereomutations as shown in the present case or different kinds of aggregation as observed in porphyrins. ${ }^{61}$ Thereby, the present work highlights the subtle but important role of monomer structure in dictating the handedness of a supramolecular assembly. At the same time, we have elucidated how the monomers' molecular design can orchestrate solvent molecules that in turn dictate supramolecular organization of the assemblies formed.

\section{ASSOCIATED CONTENT}

Supporting Information. Synthesis and characterization details of $\mathbf{C B I}-35 \mathbf{C H}$ and $\mathbf{C B I}-35 \mathbf{A C H}$, supporting figures and tables and computational details. "This material is available free of charge via the Internet at http://pubs.acs.org."

\section{AUTHOR INFORMATION}

\section{Corresponding Author}

*subi@jncasr.ac.in and e.w.meijer@tue.nl

\section{Author Contributions}

All authors have given approval to the final version of the manuscript.

\section{Funding Sources}

The authors thank JNCASR and DST, India and the Dutch ministry of education, culture and science (FMS Gravitation program 024.001.035) for financial support. C. Kulkarni thanks Marie Skłodowska-Curie (704830) post-doctoral fellowship for financial support.

\section{ACKNOWLEDGMENT}

C. Kulkarni, K. K. Bejagam and S. J. George thank Prof. S. Balasubramanian of JNCASR for access to computational facility and for fruitful discussions. C. Kulkarni thanks Krishnendu Jalani for providing coronene dianhydride starting material and Dr. Umesh Mogera for AFM measurements.

\section{REFERENCES}

(1) Yashima, E.; Maeda, K.; Iida, H.; Furusho, Y.; Nagai, K. Chem. Rev. 2009, 109, 6102.

(2) Yashima, E.; Ousaka, N.; Taura, D.; Shimomura, K.; Ikai, T.; Maeda, K. Chem. Rev. 2016, 116, 13752.

(3) Palmans, A. R. A.; Meijer, E. W. Angew. Chem. Int. Ed. $\mathbf{2 0 0 7}, 46,8948$.

(4) Hol, W. G. J. Prog. Biophys. Mol. Bio. 1985, 45, 149.

(5) Wierenga, R. K.; De Maeyer, M. C. H.; Hol, W. G. J. Biochemistry 1985, 24, 1346.

(6) Browne, W. R.; Feringa, B. L. Nat. Nano 2006, 1, 25.

(7) Naaman, R.; Waldeck, D. H. J. Phys. Chem. Lett. 2o12, 3, 2178.

(8) Mondal, P. C.; Kantor-Uriel, N.; Mathew, S. P.; Tassinari, F.; Fontanesi, C.; Naaman, R. Adv. Mater. 2015, 27, 1924.

(9) Stone, M. T.; Fox, J. M.; Moore, J. S. Org. Lett. 2oo4, 6, 3317.

(10) Osswald, P.; Reichert, M.; Bringmann, G.; Würthner, F. J. Org. Chem. 2007, 72, 3403.

(11) Buendía, J.; Greciano, E. E.; Sánchez, L. J. Org. Chem. 2015, 8o, 12444.

(12) Liu, M.; Zhang, L.; Wang, T. Chem. Rev. 2015, 115, 7304.

(13) Khatri, C. A.; Pavlova, Y.; Green, M. M.; Morawetz, H. J. Am. Chem. Soc. 1997, 119, 6991.

(14) Palmans, A. R. A.; Vekemans, J. A. J. M.; Havinga, E. E.; Meijer, E. W. Angew. Chem. Int. Ed. Engl. 1997, 36, 2648.

(15) Kim, J.; Lee, J.; Kim, W. Y.; Kim, H.; Lee, S.; Lee, H. C.; Lee, Y. S.; Seo, M.; Kim, S. Y. Nat. Commun. 2015, 6.

(16) George, S. J.; de Bruijn, R.; Tomović, Ž.; Van Averbeke, B.; Beljonne, D.; Lazzaroni, R.; Schenning, A. P. H. J.; Meijer, E. W. J. Am. Chem. Soc. 2012, 134, 17789.

(17) Bouman, M. M.; Meijer, E. W. Adv. Mater. 1995, 7, 385.

(18) Watanabe, J.; Okamoto, S.; Satoh, K.; Sakajiri, K.; Furuya, H.; Abe, A. Macromolecules 1996, 29, 7084.

(19) Suzuki, N.; Fujiki, M.; Kimpinde-Kalunga, R.; Koe, J. R. J. Am. Chem. Soc. 2013, 135, 13073.

(20) Nakano, Y.; Ichiyanagi, F.; Naito, M.; Yang, Y.; Fujiki, M. Chem. Commun. 2012, 48, 6636.

(21) Fujiki, M. J. Organomet. Chem. 2003, 685, 15.

(22) Fujiki, M. J. Am. Chem. Soc. 2ooo, 122, 3336.

(23) Nagata, Y.; Nishikawa, T.; Suginome, M. J. Am. Chem. Soc. 2014, 136, 15901. 
(24) Nagata, Y.; Kuroda, T.; Takagi, K.; Suginome, M. Chem. Sci. 2014, 5, 4953.

(25) Yamamoto, T.; Adachi, T.; Suginome, M. ACS Macro Lett. 2013, 2, 790.

(26) Nagata, Y.; Takeda, R.; Suginome, M. Chem. Commun. $2015,51,11182$.

(27) Brunsveld, L.; Folmer, B. J. B.; Meijer, E. W.; Sijbesma, R. P. Chem. Rev. 2001, 101, 4071.

(28) Janssen, P. G. A.; Ruiz-Carretero, A.; González-Rodríguez, D.; Meijer, E. W.; Schenning, A. P. H. J. Angew. Chem. Int. Ed. 2009, 48, 8103 .

(29) Kumar, M.; Reddy, M. D.; Mishra, A.; George, S. J. Org. Biomol. Chem. 2015, 13, 9938.

(30) Kumar, M.; Jonnalagadda, N.; George, S. J. Chem. Commun. 2012, 48, 10948.

(31) Kumar, M.; Brocorens, P.; Tonnelé, C.; Beljonne, D.; Surin, M.; George, S. J. Nat. Commun. 2014, 5, 5793.

(32) Gillissen, M. A. J.; Koenigs, M. M. E.; Spiering, J. J. H.; Vekemans, J. A. J. M.; Palmans, A. R. A.; Voets, I. K.; Meijer, E. W. J. Am. Chem. Soc. 2014, 136, 336.

(33) Cantekin, S.; Nakano, Y.; Everts, J. C.; van der Schoot, P.; Meijer, E. W.; Palmans, A. R. A. Chem. Commun. 2012, 48, 3803.

(34) Ajayaghosh, A.; Varghese, R.; George, S. J.; Vijayakumar, C. Angew. Chem. Int. Ed. 2006, 45, 1141.

(35) Korevaar, P. A.; de Greef, T. F. A.; Meijer, E. W. Chem. Mater. 2014, 26, 576.

(36) Korevaar, P. A.; George, S. J.; Markvoort, A. J.; Smulders, M. M. J.; Hilbers, P. A. J.; Schenning, A. P. H. J.; De Greef, T. F. A.; Meijer, E. W. Nature 2012, 481, 492.

(37) Lohr, A.; Lysetska, M.; Würthner, F. Angew. Chem. Int. Ed. 2005, 44, 5071.

(38) van der Zwaag, D.; Pieters, P. A.; Korevaar, P. A.; Markvoort, A. J.; Spiering, A. J. H.; de Greef, T. F. A.; Meijer, E. W. J. Am. Chem. Soc. 2015, 137, 12677.

(39) Ogi, S.; Stepanenko, V.; Thein, J.; Würthner, F. J. Am. Chem. Soc. 2016, 138, 670.

(40) Adelizzi, B.; Filot, I. A. W.; Palmans, A. R. A.; Meijer, E. W. Chem. Eur. J. 2017, 23, 6103.

(41) Ogi, S.; Fukui, T.; Jue, M. L.; Takeuchi, M.; Sugiyasu, K. Angew. Chem. Int. Ed. 2014, 53, 14363.

(42) Aparicio, F.; Nieto-Ortega, B.; Nájera, F.; Ramírez, F. J.; López Navarrete, J. T.; Casado, J.; Sánchez, L. Angew. Chem. Int. Ed. 2014, 53, 1373.

(43) Valera, J. S.; Sánchez-Naya, R.; Ramírez, F. J.; Zafra, J. L.; Gómez, R.; Casado, J.; Sanchez, L. Chem. Eur. J., 2017, 23, 11141.

(44) Ogi, S.; Sugiyasu, K.; Manna, S.; Samitsu, S.; Takeuchi, M. Nat. Chem. 2014, 6, 188.

(45) Fukui, T.; Kawai, S.; Fujinuma, S.; Matsushita, Y.; Yasuda, T.; Sakurai, T.; Seki, S.; Takeuchi, M.; Sugiyasu, K. Nat. Chem. 2017, 9, 493.
(46) Dhiman, S.; Jain, A.; George, S. J. Angew. Chem. Int. Ed. $2017,56,1329$.

(47) Jonkheijm, P.; van der Schoot, P.; Schenning, A. P. H. J.; Meijer, E. W. Science 2006, 313, 80.

(48) Berrocal, J. A.; Di Meo, F.; Garcia-Iglesias, M.; Gosens, R. P. J.; Meijer, E. W.; Linares, M.; Palmans, A. R. A. Chem. Commun. 2016, 52, 10870 .

(49) Nakano, Y.; Hirose, T.; Stals, P. J. M.; Meijer, E. W.; Palmans, A. R. A. Chem. Sci. 2012, 3, 148.

(50) George, S. J.; Tomovic, Z.; Schenning, A. P. H. J.; Meijer, E. W. Chem. Commun. 2011, 47, 3451.

(51) Isare, B.; Linares, M.; Zargarian, L.; Fermandjian, S.; Miura, M.; Motohashi, S.; Vanthuyne, N.; Lazzaroni, R.; Bouteiller, L. Chem. Eur. J. 2o10, 16, 173.

(52) Nakano, Y.; Markvoort, A. J.; Cantekin, S.; Filot, I. A. W.; ten Eikelder, H. M. M.; Meijer, E. W.; Palmans, A. R. A. J. Am. Chem. Soc. 2013, 135, 16497.

(53) Johnson, R. S.; Yamazaki, T.; Kovalenko, A.; Fenniri, H. J. Am. Chem. Soc. 2007, 129, 5735.

(54) Liu, C.; Jin, Q.; Lv, K.; Zhang, L.; Liu, M. Chem. Commun. 2014, 50, 3702.

(55) Kulkarni, C.; Munirathinam, R.; George, S. J. Chem. Eur. J. 2013, 19, 11270.

(56) Alibert-Fouet, S.; Seguy, I.; Bobo, J.-F.; Destruel, P.; Bock, H. Chem. Eur. J. 2007, 13, 1746.

(57) Smulders, M. M. J.; Nieuwenhuizen, M. M. L.; de Greef, T. F. A.; van der Schoot, P.; Schenning, A. P. H. J.; Meijer, E. W. Chem. Eur. J. 2010, 16, 362.

(58) It has been previously shown that kinetic studies are needed to unambigiously assign inter vs intra-assembly processess. $3^{8}$ However, due to the very low operating temperature, such studies were not successful. Based on negligible change in UV-vis spectra, we attribute the helical transition to intra-assembly process.

(59) CRC Handbook of Chemistry and Physics, 93 ${ }^{\text {rd }}$ ed.; Haynes, W. M. Ed.: CRC Press, Boca Raton, FL, 2012.

(6o) The linear $n$-heptane and branched iso-octane data is not included in Fig $5 \mathrm{~b}$ because the trend is observed within the family of cyclic or linear solvents and data across different class of solvents cannot be compared due to the different geometry and transition temperature with the assembly of $\mathbf{C B I}-35 \mathbf{C H}$.

(61) van der Weegen, R.; Teunissen, A. J. P.; Meijer, E. W. Chem. Eur. J. 2017, 23, 3773. 


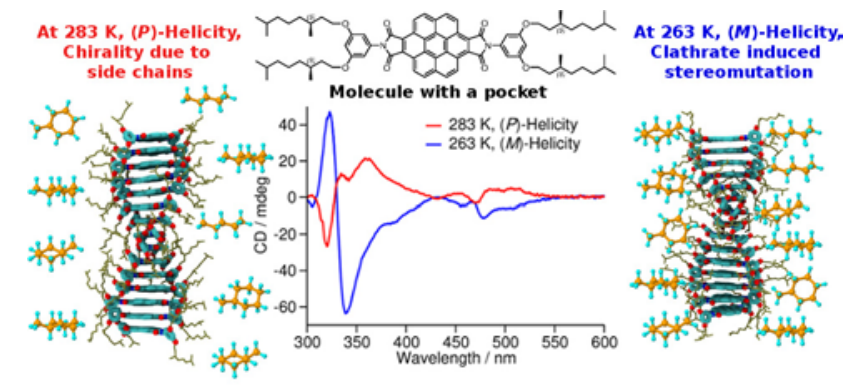

